\title{
Giving Appropriate Examples to Help Students in Gaining Their Conceptual Change
}

\author{
Ronal Rifandi \\ Universitas Negeri Padang
}

In the 21 st century world, mathematics will not be taught as a solely subject, there are an arising approach in teaching where science, technology, engineering and mathematics are integrated together (Rifandi \& Rahmi, 2019). However, the important part of a successful learning process is shown by the change that happened in students mind which is from their prior knowledge into a new knowledge. A question is "what can teacher do to help student to be success in gaining the conceptual change in mathematics?".

The use of students' initial knowledge is important in order to bridge their real world life with the theory in mathematics (Rifandi, 2017). Nowadays, we already have many studies that try to answer this question. However, since we talk about student, a human being, the discussion will always dynamic. This article explains the conceptual change definition, the factors that influence it and the use of appropriate examples (abstract or concrete examples) as one of the strategies to help students, especially in learning mathematics. Choosing right examples in learning process is my suggestion to answer the question in the beginning of this essay.

To begin with, what is conceptual change? As Vosniadou (2003) state in her article, conceptual change is the outcome of a complex cognitive as well as social process thereby which an initial framework theory is reconstructed. Based on this definition, we know that the shift of student knowledge from the initial one to a next cognitive level is not a solely process. It is not as simple as distributing the knowledge but many factors play roles in the process. Moreover, in education, we have term of facilitate. The learning processes have to facilitate the student in order to involve them in a higher cognitive level. It means facilitate them in gaining their conceptual change.

Furthermore, Vosniadou (2003) deliver that there are four variables that influence the process of conceptual changes. They are individual cognitive change, individual motivational and affective variables, educational setting, and broader social and cultural environments. I want 
to focus on the third variable. It is about the educational settings especially in the choosing of examples in mathematics classroom.

There are two main opinions about the examples that can be used in the classroom mathematics. On the one hand, Kaminski, Sloutsky and Heckler (2008) claimed that students may benefit more from learning a single abstract instantiation rather than multiple concrete instantiation. On the other hand, De Bock and his team (2011) stated that transfer in a new concrete domain is also enhanced more by concrete instantiations than by abstract instantiations. These two studies had weaknesses for instance the unfairness condition of variable in Kaminski et.al studies and the unclear explanation of why the students which learn in concrete learning domain had lower score in the abstract transfer domain in De Bock et.al Studies. However, it is pointed out the message that they want to share about the choosing of right instantiation in learning process.

In conclusion, teachers have to aware about the way they design and create the activities regarding the goal of helping students in gaining the conceptual change. Because, the right instantiation whether it is concrete or abstract, depend on the necessity regarding the material, will lead to a better change from the prior knowledge of the students into the next cognitive level.

\section{REFERENCES}

De Bock, D.,Deprez, J., Van Dooren, W., Roelens, M., \& Verschaffel, L. (2011). Abstract or Concrete Examples in Learning Mathematics? A Replication and Elaboration of Kaminski, Sloutsky, and Heckler's Study. Journal for Research in Mathematics Education, 42, 109-126.

Rifandi, R. (2017). Supporting students' reasoning about multiplication of fractions by constructing an array model. JRAMathEdu (Journal of Research and Advances in Mathematics Education), 1(2), 99-110.

Rifandi, R., \& Rahmi, Y. L. (2019, October). STEM education to fulfil the 21st century demand: a literature review. In Journal of Physics: Conference Series (Vol. 1317, No. 1, p. 012208). IOP Publishing. 
Kaminski, J. A., Sloutsky, V. M., \& Heckler, A. F. (2008a). The advantage of abstract examples in learning math. Science, 320, 454-455.

Vosniadou, S. (2003). Exploring the relationships between conceptual change and intentional learning. Intentional conceptual change, 377-406. 